\title{
Effect of Awareness of Teacher Education Philosophy on EFL Teachers' Professional Knowledge: A Postmethod Perspectivisation
}

\section{Ghasemali Azadi Renani}

PhD Candidate, Department of English, Isfahan Branch (Khorasgan), Islamic Azad University, Isfahan, Iran, azadi62@ hotmail.com

\author{
Akbar Afghari \\ Assoc. Prof., Corresponding author, Department of English, Isfahan Branch \\ (Khorasgan), Islamic Azad University, Isfahan, Iran, drakafghari20@ hotmail.com

\section{Bahram Hadian} \\ Assoc. Prof., PhD, Department of English, Isfahan Branch (Khorasgan), Islamic Azad \\ University, Isfahan, Iran, bah_hadian@yahoo.com
}

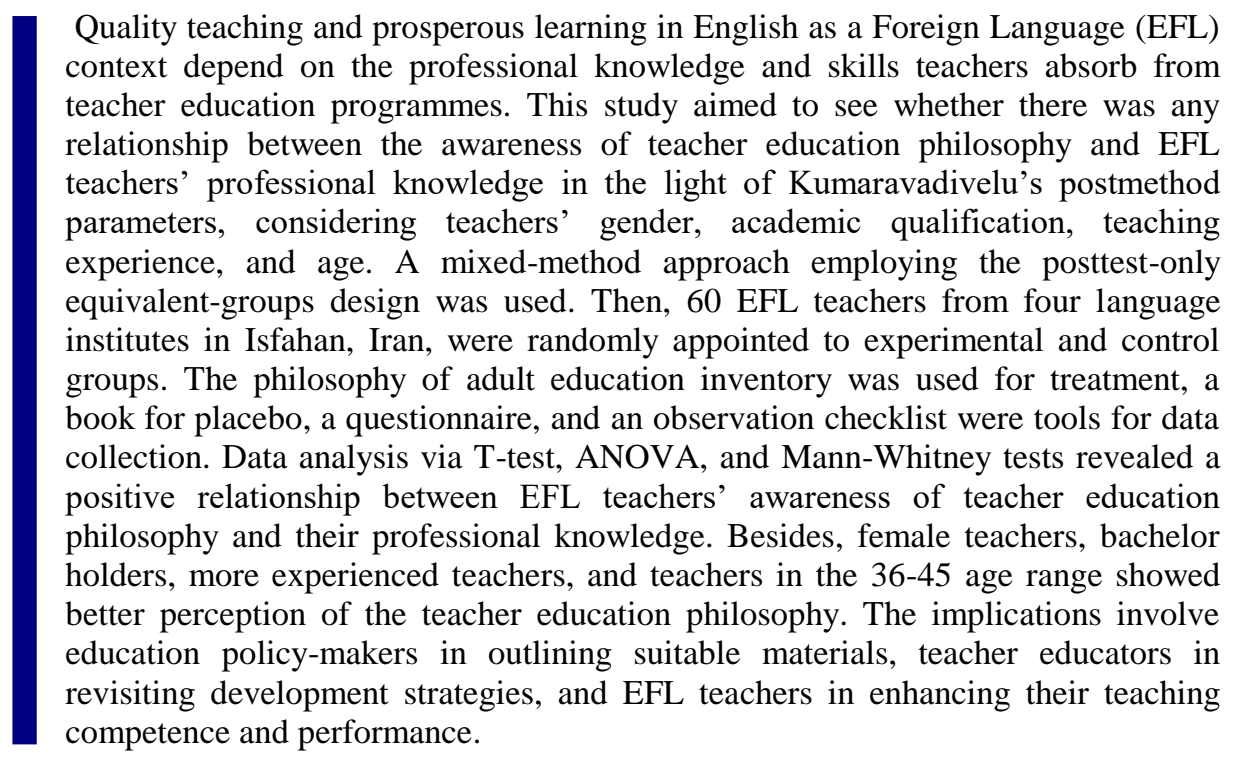

Keywords: teacher awareness, teacher education philosophy, EFL teachers, professional knowledge, postmethod parameters 


\section{INTRODUCTION}

EFL teacher acts as a professional organiser of the teaching and learning process as well as an expert presenter of knowledge and skills by considering variables like instructional purposes, students' characteristics, classroom conditions, and methodological aspects. The teacher is provided with the numerous theoretical premises and practical approaches addressing alluded variables in the teacher education programmes. The programmes held either for pre-service or in-service teachers should pursue educational philosophies to insert insight into every aspect of teacher's professional knowledge (PK) and every step of professional skills (PS) in the classroom. Accordingly, teacher needs to know the role of philosophy in teacher education as an axiom that helps teacher experience an inclusive revival of theory and practice, offers conceptual frameworks for participant teacher, re-evaluates the purpose of teaching and learning, clarifies educational issues, and makes room for research (Winch, 2012). Besides, teacher needs to closely track teacher education philosophy (TEP) presented in the programmes to recognise and rectify past ideas and practices, to command the present theoretical and practical facets, and to form new understandings and intentions regarding optimal teaching and learning (Buchmann \& Feloden, 1990).

To highlight the value of TEP in EFL context, Erkilic (2008) encourages teacher to continuously experiment and evaluate his/her professional efforts to ensure whether they follow competence and prosperity of teaching and learning pursuant to TEP. It reveals a strong connection between what drives language teachers into the profession as profound inspiration and how they teach assigned and unassigned materials as hands-on presentation (Cattley, 2007 \& Trent, 2010). TEP is vital in equipping teachers with insight into the reasons of presenting materials and teaching techniques, broadening teachers' horizon for more weighty resolution, refreshing teachers' minds for sharp assertion, updating their PK and PS for ideal classroom outcome, and paving the way for prolific teaching and learning. TEP inspires teachers so richly that they almost always stay on the right track as informed and informative affective teachers (Czerniawski, 2011).

An effective teacher, in accordance with the learners' requirement and classroom setting, needs to consider three branches of philosophy- metaphysics involving in reality; axiology dealing with values; and epistemology centring on knowledge. Teacher, as an intellectual individual, needs to perceive the educational philosophies, from olden and modern epochs, to prepare the ground for more advantageous teaching and learning since they have impacted teaching/learning and teacher/learner to the extent that they have altered theories and practices from premodern to postmodern era. Among the philosophies of the olden time still influencing educational theories and practices, there exist Socratic philosophy of reasoning, Platonic philosophy of interrogation, and Aristotelian philosophy of experimentation (Dwyer, Maruyama \& Fontaine, 2011). Of the philosophies in modern era, five major educational ones counting Idealism, Realism, Pragmatism, Existentialism, and Postmodernism need profoundly recognising by teachers to teach with inclusive, meticulous, and logical insight. 
Idealism focuses on truths and values as universally absolute attributes and on the aim of education as the development of the intellectual capacity in students through helping them appreciate extensive ideas and principles. Teacher, in the framework of Idealism, is respected for having knowledge of the certain universal ideas, teaching the key concepts and principles from the classics, guiding students in their search for truth, and promoting thinking in the students. The Socratic method is especially suitable for inspiring the learner's awareness of ideas with the teacher asking principal questions (Tan et al., 2006). The main criticisms of Idealism represent that it promotes intellectual elitism where only a gifted minority of intellectuals are valued in society and it may lead to a neglect of the students' emotional and social needs (Ornstein \& Levine, 2003).

Realism came into existence claiming that the pitfalls of Idealism derail teachers and students' long-term perspectives and accountabilities at individual and social status. Realistic attention turned to the tangible and physical world as core consideration, the essential reasoning and experiencing for knowledge attainment, and the instrumental function of knowledge. According to Crookes (2009), the schools, in Realism, should help students rely on aptitudes reinforced by logical explanation, obvious observation, and assessable experimentation in line with vocational qualifications and skills. Teacher, then, is an expert in the textbook materials, content explanation, and standard assessments pursuant to the life facts, logical reasons, and practical implementations. However, the criticism goes to overvaluing student's cognitive development, ignoring student's feelings, and restricting students to a prepared curriculum. (Ozmon \& Craver, 2003).

Pragmatism places emphasis on reality as an ever-changing phenomenon based on the learner's observation and experience. Knowledge is used to grow learner's social relationship, problem-solving ability, and democratic living through exposing the learners to real life events (Gutek, 2004). It is a highly student-oriented philosophy since their interests, needs and problems are closely considered and pursued in a practical environment. A pragmatic teacher as a resource person and facilitator is not constrained to follow the textbook materials or curriculum outlines for s/he presents topics in the classroom based on students' interests and needs relevant to their real lives. Teacher guides students in conducive learning, collaborative environment, and problem solving to the point that it assists them to prepare resolution to some social and individual predicaments (Tan, et al., 2006). The drawbacks of this philosophy are not only to underrate the stages of learning, standard materials for the school year, and designed curriculum by educational experts, but also to exaggerate the permanent change in values and realities (Ozmon \& Craver, 2003).

Existentialism denies universal and absolute ideas and weighs on individual values. Every individual appears unique in thought, emotion, and needs as well as being free to pick up or learn the knowledge according to his own needs originated from personal fears, hopes and aspirations (Ornstein \& Levine, 2003). Strict school and fixed curriculum are severely criticised due to suppressing student's individuality, dehumanising student's personal values, and prioritising the needs of society rather than students' personal preferences. Students are encouraged to express their topics and 
choices to be addressed and pursued in a creative environment for possible solutions. Accordingly, an existentialist teacher contemplates student's individuality, freedom, and options, follows reflective comments and philosophical dialogue about students' reallife issues, and even provides the environment for students to set their own assessment (Gutek, 2004). Not having adequately emphasised the importance of needs of the society, existentialist teaching doctrine leads students to selfishness and egoism (Ozmon \& Craver, 2003).

Postmodernism abandons enlightenment assertion in which scientific methods should be implemented to account for objectivity and universality. Schools should discard the programmed curriculum and prearranged syllabi that impose knowledge; instead, they should empower students to criticise the traditional perspectives as well as the dominant accounts. They should also initialise a variety of standpoints based on the needs of all individuals even ones from the marginalised groups. The focal feature of postmodernism for the teacher and student is to distance themselves from the politically and ideologically dominated and assigned decrees in the educational context and, instead, to centre on social and cultural factors salient for students in the classroom so that students' particular identities, interests, and concerns are well respected. However, Gutek (2004) argues that postmodernist rejection of universal aspects of values causes a kind of relativism in real-life events and diminish moral and rational ideals in teaching context.

Postmodernism paves the way for postmethod pedagogy reinforced by critical theory in language classroom to analyse unfair relationships and expectations in the school and society and to encourage both teacher and student to tackle the relevant problems for equality, fairness and justice (Gutek, 2004). The pedagogy respects the viewpoints and experiences of all students especially ethnic, language, class and gender groups. According to Ornstein \& Levine (2003), teacher in postmethod opposes traditional pedagogy, pursues culturally diverse events, encourages collaborative actions, holds critical dialogues with students, and involves students in solving society's major problems.

Teacher education as mainstream approach in L2 "has frequently lacked a social or political dimension that helps locate English and English language teaching within the complex social, cultural, economic, and political environments in which it occurs." (Pennycook, 2004, p. 335). The reason is most models of teacher education are designed to transmit a set of pre-specified body of knowledge from the teacher educators to the teachers. In such top-down approaches teacher educators offer teachers suggestions on the best way to teach, model appropriate teaching behaviours, and finally evaluate their mastery of such pedagogical behaviours. Such a transmission model of teacher education is inadequate to produce autonomous and creative teachers who constitute the backbone of any postmethod pedagogy (Kumaravadivelu, 2006). In postmethod framework, pedagogy appoints the responsibility of teacher educator to create conditions for more competent teachers to acquire necessary authority and autonomy that will enable them to reflect on and shape their own professional experiences to offer them in the classroom when needed. In other words, it becomes necessary to have 
teacher education that does not merely transmit a body of knowledge, but rather one that is dialogically created by participants who think and act critically.

\section{LITERATURE REVIEW}

Philosophy of education raises questions of what teacher needs to do as well as why teacher needs to do it in the classroom. A working philosophy of education, according to Brookfield (1990), provides the answers to "why you're doing what you're doing" (p. 16). The emphasis is placed on the why of teacher education and on the ideals, attitudes, and beliefs the teacher educator teaches during the programmes (Elias \& Merriam, 2005; Kumar, 2015). Day and Amstutz (2003) put, "holding one set of beliefs does not eliminate the possibility of holding additional belief-sets" (p. 93). Furthermore, to understand the educational process with novel insight, Fries (2012) believed that teachers must consider their experiences and use critical reflection to be aware of not only what decisions they make, but also why they make decisions in the teaching and learning environment. Galbraith (1999) believed "a working or guiding philosophy of educational practice provides the foundation and reasons for all decisions, processes, and actions made about the instructional and learning process" (p. 11).

Zinn (2007) revised the Philosophy of Adult Education Inventory (PAEI) representing a comprehensive and interrelated set of values and beliefs as applied to education including reasons about the purpose and nature of human life, the role of the individual in society, purposes or goals of education, role of teachers and learners, important subject matter, and effective teaching approaches. Further, Merriam and Brockett (2007) pointed out that a philosophy for education typically includes terms, reasons, aims, and the roles of teacher such as responsibility for selecting and making decisions regarding the material and content they will cover in their coursework. Therefore, they often choose what they believe is the most effective way of incorporating this material into their syllabi, learning sessions, assignments, etc. While this is true, Conti (2004) asserted that teachers are often unable to state their beliefs about teaching because an educator's personal philosophy provides them with a strong basis for making decisions and taking actions in the practice of instruction.

According to Elias and Merriam (1980), there are approaches defining a personal philosophy including (1) teachers choose a particular theoretical framework and build an educational philosophy upon it; (2) teachers choose non-conflicting theories and specific elements and create an eclectic philosophical approach; or (3) teachers choose one philosophy or determine their approach that is already espoused. However, Apps (1985) believed that teachers can develop a working philosophy by considering some philosophic questions and using a scientific method of analysis in which the reasons for teaching practices can be detailed. The philosophic questions would centre on the learner, purpose of education, content/subject matter, the learning process, and the teachers' beliefs. Following the scientific approach of analysis, a teacher can build upon his philosophy as needed by identifying an educational philosophy, reviewing the framework critically, determining how best his values and beliefs fit within the theories, and adjusting his teaching practices to align with the philosophical schema. 
Moreover, Langford (2005) introduced Instruction Practice Model of Teaching (IPMT) as a new view to philosophy of teaching in which teachers need to be exposed to the reasons of principles presented in purposeful and conscious manners; to receive activities that enable them to test their understanding of the principles; and to practice them in real context with strong reasoning. This model acts as a source for teachers to receive formal instructions for the classroom along with the rationale underlying instructions and then deliver the instructions to the students to enable them to apply the principles more meaningfully.

Holzman (2009) emphasised that teacher in L2 context must discover and make apparent reasons and available resources appropriate to teach materials chosen in the classroom. To do so, teacher education programmes should provide 'supplemental education' to portray the picture of philosophy of teaching from what a teacher learns in the programmes, why they learn it and how students learn it from a teacher. Supplemental education considers views underlining the part of classroom practice package regarding knowledge and skill that lead to quality academic achievement by both teacher and student.

In postmethod teacher education, teacher does not transmit a body of knowledge, but rather he supports the environment that is dialogically created by participants who think and act critically. According to Bakhtin (1981), dialogic interaction in which all the participants have the opportunity and the autonomy to express their voice and exhibit their personality and profession facilitates an interaction between meanings and belief systems; an interaction that produces what Bakhtin calls, "a responsive understanding" (p. 280). Thus, the primary responsibility of the teacher education is not to provide the teacher with a predetermined professional knowledge, but to provide opportunities for the dialogic construction of meaning out of which L2 teachers' personality or voice may emerge.

Dialogic teacher education, through purposeful interactions, opens channels of communication between student-teachers and teacher-educators hitting problem solving processes through critical procedures (Kumaravadivelu, 2012). Teachers actively and freely use the linguistic, cultural and pedagogic repertoire they bring with them and teacher educators show willingness to use the teacher's values, beliefs, and knowledge as an indispensable part of the learning process. Johnson (2006), in line with recent trends, explained that "L2 teachers learn normative and lifelong knowledge and skills emerging principally out of and through experiences in social context while they act as critical thinkers who try to seek the reasons for each teaching activity in classrooms." (p. 239).

\section{Postmethod Theory}

Postmethod theory, which has taken its supporting basis from postmodern philosophy, is pioneered by Derrida (1982) and Foucault (1997) and outlined in education by Giroux (1999). Giroux founded "Border Education" in which many certain goals of traditional system of education are turned down and provides teachers and learners with multi resources of thoughts, cultures, and experiences. In Border Education, teacher is 
considered an intellectual who respects multi-dimensional atmosphere both inside and outside the classroom and should be equipped with knowledge to be a professional intellectual. Student, in such education, is encouraged to think and analyse whatever they read and hear and constructs new concepts and interpretations. Accordingly, teaching lies in dialogue, discourse, and critical thinking held bilaterally to prepare students for a real world outside the classroom.

Postmethod theory considers the teacher education as learning processes, instead of merely handling materials, in which everything is based on the freely chosen issues originated from values, traditions, beliefs, school-oriented communities and the requirements of a learner in the real world. Such issues are selected in a collaborated teamwork between student-student and teacher-student who look for solving not only problems presented within the discussions inside the classroom, but also serious issues outside the classroom. In other words, postmethod theory takes the details into consideration and follows various teaching methods pursuant to the teachers' and students' interests and traits targeting real life issues.

\section{Kumaravalivelu's Postmethod Model of Teacher Education}

Postmethod teacher education embracing three parameters of particularity, practicality and possibility was put forward and trimmed by Kumaravadivelu (2001, 2008, \& 2012). Tapping three parameters, the educationists contemplate the inherent flaws of the traditional approaches to L2 teacher education programmes as sequential courses focusing on discrete presentations of content areas as barren. Postmethod model disregards L2 teacher education programmes that offer a series of prearranged course in areas such as pedagogical theories, second language acquisition, teaching methods, school curriculum, and testing.

Based on Kumaravadivelu (2012), traditional or predetermined teacher education courses are unable to tackle the challenging priorities in the postmodern era. Therefore, L2 present and prospective teachers prefer production of personal knowledge to application of received wisdom, acceleration of agency to acceptance of authority, teacher research with local touch to expert research with global reach, become transformative intellectuals to be passive technicians, master the teaching model to model the master teacher, and think critically and make students think critically to take teaching techniques and learning steps for granted.

This model distances teacher from linear, discrete, additive, and compartmentalised character of teacher education by providing a cyclical, integrated, interactive, multidirectional and multidimensional process since it "constitutes a network of mutually reinforcing sub-systems with a dialectical interplay resulting in a holistic learning and teaching environment" (Kumaravadivelu, 2012, p. 17). The model includes five constituent modules- Knowing, Analysing, Recognising, Doing, and Seeing (KARDS) that teacher must learn in teacher education programmes and implement them as an effective teacher. Thus, teacher education is treated not as the source of experience and interpretation of predetermined or prescribed pedagogic practice presented by 
teacher educators, but rather as an ongoing and dialogically constructed entity involving critically reflective participants in the light of particularity, practicality and possibility.

\section{Particularity, Practicality, and Possibility}

Particularity entails "a particular group of teachers teaching a particular group of learners pursuing a particular set of goals within a particular institutional context embedded in a particular sociocultural milieu" (Kumaravadivelu, 2001, p. 538). The parameter of particularity rejects the method-based perceptive that dictates a fixed set of teaching principles and procedures predetermined to put to application. This parameter focuses on local requirements and experiences to stress the need for language teaching and learning to be sensitive to the linguistic particularities of even nonstandard speakers of English (Smitherman, 2000).

Practicality focuses on the relationship between theory and practice and teacher's skill in monitoring his own teaching effectiveness. The distinction is made between professional theories by experts transmitted via centres of higher learning and personal theories developed by teachers through interoperating and applying them in practical situations in the classrooms (O'Hanlon, 1993). When context-sensitive pedagogic knowledge emerges from teachers and their practice of everyday teaching in the classroom, they will theorise from their practice and practice what they theorise. In this regard, Edge (2001) states that "the thinking teacher is no longer perceived as someone who applies theories, but someone who theorises practice" (p. 6). This two-way trend can be achieved by helping teachers develop the knowledge and skill in teacher education programmes to construct their context-sensitive theory and practice.

Possibility emphasises knowledge and experience that people bring to pedagogical setting. Such knowledge and experience are shaped not just by what they experience in the classroom, but also by a broader social, economic, and political environment in which they grow up (Kumaravadivelu, 2012). These experiences have the potential to alter classroom aims and activities in ways unintended and unexpected by policy planners, curriculum designers, or textbook producers. It also addresses language ideology and learner identity that make teachers and learners mull over inside-andoutside-classroom activities based on their worldviews and values. As Norton (2000) puts, language and language classroom construct personality of learners both historically and socially and influence the subject position learners take up in the language classroom and the relationship they establish with the language teacher. This is more applicable to L2 education which brings languages and cultures in contact and attempts to address the real-life affairs.

The purpose of this study was to examine the effect of EFL teachers' awareness of TEP on their PK regarding their gender, academic qualification, teaching experience, and age. The present study addresses the following questions:

Does EFL teachers' awareness of TEP affect the PK of male and female teachers?

Does EFL teachers' awareness of TEP affect their PK at two levels of academic qualification? 
Does EFL teachers' awareness of TEP affect their PK at three levels of teaching experience?

Does EFL teachers' awareness of TEP affect their PK in three age ranges?

\section{METHOD}

The research strategy for data collection and data analysis associated with the questions was an explanatory sequential mixed-method research comprising true experimental design and the posttest-only equivalent-groups plan (Best \& Khan, 2006).

\section{Participants}

The participants included $60 \mathrm{EFL}$ teachers selected through cluster random sampling from four institutes in Isfahan, Iran and were divided in half as the experimental and control groups. Both groups consisted of males and females, held B.A or M.A, had teaching experience between 1-10,11-20 and plus 20, and ranged in three age groups from $25-35,36-45$ to plus 45 .

\section{Instruments}

The instruments of the study included the Philosophy of Adult Education Inventory (PAEI) from Zinn (2007), a questionnaire from Renani (2011), and an observation checklist from Hug's (2015). Three university lecturers majored in testing confirmed the validity of the instruments and the calculated Cronbach's Alpha for internal reliability of the instruments represented $.87, .77$, and .83 respectively. PAEI was presented to the experimental group for treatment process in a teacher education programme. The inventory was a 15 -item package consisting of 75 options to be dialogically discussed and marked in a five-band Likert scale from Strongly disagree to Strongly agree. Moreover, a book termed 'Techniques \& Principles in Language Teaching' by LarsenFreeman and Anderson (2011) was provided for the control group as placebo and the group was requested to read it for four weeks.

The 20-item questionnaire about PK comprised equal statements for principles of language teaching, classroom creative tasks, reflection on students' involvement, and solutions to classroom problems. It was distributed to both experimental and control groups a week after terminating teacher education programme and book-reading period. The items were marked by participants in a five-band Likert scale from Strongly disagree to Strongly agree. To see the validity assurance of the research, the 20-item classroom observation checklist was developed for Iranian context and employed to record the presence or absence of the teaching attributes concerning postmethod parameters for teaching the English language and to ascertain the effect of TEP on teachers' PK. Digit 1 for present attributes and digit 0 for absent ones were jotted down.

\section{Procedure}

Having randomly selected four English language institutes in the city of Isfahan, the researchers assigned $60 \mathrm{EFL}$ teachers to experimental and control groups through cluster sampling. After obtaining the validity of PAEI through the viewpoints of three TEFL 
experts, the experimental group received treatment by attending an eight-session teacher education programme held in four consecutive weeks. Each two-hour session was oriented to two/three items including 10-15 options from the PAEI. Every single option of the inventory was examined in constructive dialogues to elicit the EFL teachers' awareness of TEP in line with assisting the teacher to identify insight into teaching knowledge, building up his personal philosophy on teaching practices, and comparing it with prevailing philosophies in the field of language teaching. As the experimental group got engaged in treatment trend, a four-week-book-reading period was specified for the control group during which the group was required to study the provided book over techniques and principles in language teaching.

A week after the treatment for experimental group and book-reading period for control group, both groups received a questionnaire a week later. The questionnaire included 20 items on the aspects of PK as the major concern areas in the classroom context among Iranian EFL teachers to be marked from Strongly disagree to Strongly agree. To see if the participant teachers who received treatment and book-reading period were compatible with the results of the questionnaires in practice, a classroom observation protocol with the use of a 20 -item checklist for postmethod pedagogy in Iranian context was implemented in 20 classrooms.

\section{FINDINGS}

For the first research question, the scores of the male teachers in both groups were compared through an independent-sample t-test. Table 1 shows the results of descriptive statistics and t-test results comparing the scores of the experimental group male (EGM) teachers and their control group male (CGM) counterparts.

Table 1

Independent-sample T-test Comparing the Scores of the EGM and CGM Teachers

\begin{tabular}{llllllll}
\hline Groups & $\mathrm{N}$ & Mean & $\begin{array}{l}\text { Std. } \\
\text { Deviation }\end{array}$ & $\begin{array}{l}\text { Mean } \\
\text { Difference }\end{array}$ & t & df & $\begin{array}{l}\text { Sig. } \\
\text { (2-ailed) }\end{array}$ \\
\hline EGM & 15 & 70.73 & 11.04 & 21.57 & 6.05 & 26 & .00 \\
\hline CGM & 13 & 49.15 & 7.01 & & & & \\
\hline
\end{tabular}

Table 1 displays that the EGM teachers $(M=70.73)$ obtained a higher mean score vis-àvis the CGM teachers $(M=49.15)$ along with the Sig. (2-tailed) less than $(p<.05)$. The results revealed a statistically significant difference between the two groups, concluding that the treatment to which the EGM teachers had been exposed was beneficial to their PK.

Likewise, the scores of the female teachers in both groups were compared via an independent-sample t-test. To collate the scores of the experimental group female (EGF) teachers with their control group female (CGF) counterparts, descriptive statistics and ttest results appear in Table 2. 
Table 2

Independent-Sample T-test Comparing the Scores of the EGF and CGF Teachers

\begin{tabular}{llllllll}
\hline Groups & $\mathrm{N}$ & Mean & $\begin{array}{l}\text { Std. } \\
\text { Deviation }\end{array}$ & $\begin{array}{l}\text { Mean } \\
\text { Difference }\end{array}$ & t & df & $\begin{array}{l}\text { Sig. } \\
\text { (2-ailed) }\end{array}$ \\
\hline EGF & 15 & 73.00 & 7.33 & 24.29 & 8.40 & 30 & .00 \\
\hline CGF & 17 & 48.70 & 8.80 & & & & \\
\hline
\end{tabular}

Table 2 indicates a larger mean score for the EGF teachers $(M=73.00)$ than for the CGF teachers $(M=48.70)$ and the Sig. (2-tailed) less than $(p<.05)$. Accordingly, there was a significant difference between the two groups, showing that the treatment received by the EGF teachers was useful for their PK.

For the second research question, an independent-sample t-test was run to compare the scores of the bachelor teachers in both groups. Table 3 illustrates the comparison of the scores for the experimental group bachelor (EGB) teachers and the control group bachelor (CGB) teachers.

Table 3

Independent-Sample T-test Comparing the Scores of the EGB and CGB Teachers

\begin{tabular}{llllllll}
\hline Groups & $\mathrm{N}$ & Mean & $\begin{array}{l}\text { Std. } \\
\text { Deviation }\end{array}$ & $\begin{array}{l}\text { Mean } \\
\text { Difference }\end{array}$ & $\mathrm{t}$ & df & $\begin{array}{l}\text { Sig. } \\
\text { (2-tailed) }\end{array}$ \\
\hline EGB & 15 & 73.70 & 8.07 & 24.00 & 9.15 & 35 & .00 \\
\hline CGB & 20 & 49.70 & 7.84 & & & & \\
\hline
\end{tabular}

As shown in Table 3 , the calculated mean score of the EGB teachers $(M=73.70)$ was more than that of the CGB teachers $(M=49.70)$ and the Sig. (2-tailed) was less than ( $p$ $<.05)$. The results showed a significant difference between the two groups, implying the treatment for the EGB teachers had positive impact on their PK.

The same statistical procedure was conducted for the master teachers in both groups. Table 4 represents the results of the descriptive statistics and t-test collating the scores of the experimental group master (EGM) teachers and the control group female (CGM) counterparts.

Table 4

Independent-Sample T-test Comparing the Scores of the EGM and CGM Teachers

\begin{tabular}{llllllll}
\hline Groups & $\mathrm{N}$ & Mean & $\begin{array}{l}\text { Std. } \\
\text { Deviation }\end{array}$ & $\begin{array}{l}\text { Mean } \\
\text { Difference }\end{array}$ & t & df & $\begin{array}{l}\text { Sig. } \\
(2 \text {-tailed })\end{array}$ \\
\hline EGM & 13 & 69.46 & 10.50 & 22.16 & 5.47 & 21 & .00 \\
\hline CGM & 10 & 47.30 & 8.32 & & & & \\
\hline
\end{tabular}

Table 4 shows the EGM teachers $(M=69.46)$ received a higher mean score in comparison with the CGM teachers $(M=47.30)$ and the Sig. (2-tailed) was less than ( $p$ $<.05)$. That is, there was a significant difference between the two groups, revealing that the treatment run for the EGM teachers was advantageous to their PK.

For the third research question, one-way between-groups ANOVA was conducted for the experimental and control parts of the study and the mean scores of three groups in both parts were compared (Table 5). 
Table 5

Descriptive Statistics for Years of Experience in Experimental and Control Group

\begin{tabular}{lllll}
\hline TE & $\mathrm{N}$ & Mean & Std. Deviation & Std. Error Mean \\
\hline FTEEG & 12 & 68.50 & 10.04 & 2.90 \\
\hline FTECG & 9 & 53.88 & 9.18 & 3.06 \\
\hline STEEG & 12 & 73.75 & 6.96 & 2.01 \\
\hline STECG & 18 & 46.44 & 6.53 & 1.54 \\
\hline TTEEG & 6 & 74.83 & 11.16 & 4.55 \\
\hline TTECG & 3 & 48.66 & 7.02 & 4.05 \\
\hline
\end{tabular}

Table 5. compared $\mathrm{M}=68.50$ for the first teaching experience group (FTEEG), $\mathrm{M}=73.75$ for the second teaching experience group (STEEG), and $\mathrm{M}=74.83$ for the third teaching experience group (TTEEG) in experimental part. It also contrasted $\mathrm{M}=53.88$ for the first teaching experience group (FTECG), M=46.44 for the second teaching experience group (STECG) with $\mathrm{M}=48.66$ for the third teaching experience group (TTECG) in control part.

The ANOVA results confirmed no significant difference among the three packs of teachers in either part of the study. However, to find out whether there was statistical difference between the mean scores of the teachers in the experimental and the control parts, the value under the Sig. (2-tailed) column in the independent sample t-tests was examined (Table 6).

Table 6

Independent Sample T-test for Years of Experience in Experimental and Control Group

\begin{tabular}{|c|c|c|c|c|c|c|c|}
\hline & \multirow{2}{*}{\multicolumn{3}{|c|}{$\begin{array}{l}\text { Levene's Test for } \\
\text { Equality of Variances }\end{array}$}} & \multirow{2}{*}{\multicolumn{3}{|c|}{ t-test for Equality of Means }} & \multirow[b]{3}{*}{$\begin{array}{c}\text { Mean } \\
\text { Difference }\end{array}$} \\
\hline & & & & & & & \\
\hline & F & Sig. & $\mathrm{t}$ & $\mathrm{df}$ & $\begin{array}{l}\text { Sig. } \\
(2-1\end{array}$ & iled) & \\
\hline \multirow{3}{*}{$\begin{array}{l}\text { Equal } \\
\text { assumed }\end{array}$} & .064 & & .803 & 3.418 & 19 & .003 & 14.611 \\
\hline & variances .001 & & .975 & 10.919 & 28 & .000 & 27.305 \\
\hline & .324 & & .587 & 3.645 & 7 & .008 & 26.166 \\
\hline \multirow{3}{*}{\multicolumn{2}{|c|}{$\begin{array}{l}\text { Equal variances } \\
\text { not assumed }\end{array}$}} & & & 3.464 & 18.165 & .003 & 14.611 \\
\hline & & & & 10.776 & 22.647 & .000 & 27.305 \\
\hline & & & & 4.290 & 6.252 & .005 & 26.166 \\
\hline
\end{tabular}

As can be seen in Table 6, the values in the Sig. (2-tailed) for the three groups in both parts were less at the $p<.05$. Therefore, there was a statistically significant difference between the teachers' scores in the experimental and the control group indicating that teacher education philosophy affected teachers' PK.

For the fourth research question, one-way between-groups ANOVA was run for the experimental and control parts of the study to compare the mean scores of three age groups in each part (Table 7). 
Table 7

Descriptive Statistics for Age Ranges in Experimental and Control Group

\begin{tabular}{lllll}
\hline AGE & $\mathrm{N}$ & Mean & Std. Deviation & Std. Error Mean \\
\hline FAEG & 19 & 69.68 & 9.05 & 2.07 \\
\hline FACG & 10 & 53.00 & 10.29 & 3.25 \\
\hline SAEG & 4 & 78.50 & 4.93 & 2.46 \\
\hline SACG & 15 & 46.80 & 5.64 & 1.45 \\
\hline TAEG & 7 & 74.00 & 10.42 & 3.94 \\
\hline TACG & 5 & 47.00 & 6.70 & 3.00 \\
\hline
\end{tabular}

Table 7. juxtaposed $M=69.68$ for the first age group (FAEG), $M=78.50$ for the second age group (SAEG), and $\mathrm{M}=74.00$ for the third age group (TAEG) in experimental part. Similarly, the calculated $M=53.00$ for the first age group (FACG), M=46.80 for the second age group (SACG), and $\mathrm{M=47.00}$ for the third age group (TACG) in control part were compared.

Since the ANOVA results showed no statistical difference among the three packs of teachers in each part of the study, the independent sample t-tests were used to find difference between mean scores of teachers in the experimental and the control parts and the value of the Sig. (2-tailed) was inspected (Table 8).

Table 8

Independent Samples T-test for Age Ranges in Experimental and Control Group

\begin{tabular}{|c|c|c|c|c|c|}
\hline \multicolumn{6}{|c|}{$\begin{array}{l}\text { Levene's Test for } \\
\text { Equality of Variances } t \text {-test for Equality of Means }\end{array}$} \\
\hline $\mathrm{F}$ & Sig. & $\mathrm{t}$ & $\mathrm{df}$ & $\begin{array}{l}\text { Sig. } \\
\text { (2-tailed) }\end{array}$ & $\begin{array}{l}\text { Mean } \\
\text { Difference }\end{array}$ \\
\hline 1.141 & .295 & 4.501 & 27 & .000 & 16.684 \\
\hline .491 & .493 & 10.191 & 17 & .000 & 31.700 \\
\hline .467 & .510 & 5.055 & 10 & .000 & 27.000 \\
\hline & & 4.320 & 16.457 & .000 & 16.684 \\
\hline & & 11.064 & 5.324 & .000 & 31.700 \\
\hline & & 5.452 & 9.955 & .000 & 27.000 \\
\hline
\end{tabular}

As observed, the values in the calculated Sig. (2-tailed) were significant at $p<.05$. for the three age ranges in both groups. That is, there was a significant difference between the teachers' scores in the experimental and the control groups which shows the premises of philosophy has developed teachers' PK.

The presented tables showed that the mean scores of teachers in the experimental group were significantly higher than those of control group. Besides, female teachers $(\mathrm{M}=73.00)$, bachelor teachers $(\mathrm{M}=73.70)$, the most experienced teachers $(74.83)$, and teachers in the second age range $(M=78.50)$ revealed better perception of TEP. To assess the possible statistical difference between the two groups over the data of the observation protocol, a Mann-Whitney test was run (Table 9 and 10). 
Table 9

Descriptive Statistics of Observation Checklists for Experimental and Control Groups

\begin{tabular}{lllll}
\hline Group & $\mathrm{N}$ & Mean & Median & Std. Deviation \\
\hline PKEG & 10 & 14.20 & 14.50 & 2.573 \\
\hline PKCG & 10 & 5.80 & 5.00 & 2.347 \\
\hline Total & 20 & & & \\
\hline
\end{tabular}

Table 10

Mann-Whitney Test for Experimental and Control Group

Mann-Whitney Tests PK

Mann-Whitney U 1.000

\begin{tabular}{lr}
\hline Wilcoxon W & 56.000 \\
\hline$Z$
\end{tabular}

\begin{tabular}{ll}
\hline $\mathrm{Z}$ & -3.719 \\
\hline
\end{tabular}

Asymp. Sig. (2-tailed)

Exact Sig. [2*(1-tailed Sig.)] $.000^{\mathrm{b}}$

a. Grouping Variable: Groups

b. Not corrected for ties.

As illustrated, there was a significant difference between mean and median scores of the teachers in the experimental group $(\mathrm{M}=14.20, \mathrm{Mdn}=14.50)$ and in the control group $(\mathrm{M}=5.80, \mathrm{Mdn}=5.00)$. The value in the Sig. (2-tailed) was .000 which was significant at $\mathrm{p}<.05$. Therefore, it is confirmed that philosophical grounds presented to experimental group grew teachers' PK in EFL classrooms.

\section{DISCUSSION}

The data analysis to the first question indicated a significant difference between the teachers in the experimental and the control groups over the awareness of TEP. That is, male and female teachers participated in the experimental group demonstrated better perception than that of teachers in control group. The same inference is made from the results of classroom observation data. The significant difference between two groups confirms that understanding TEP affects teachers' PK.

The cause of better awareness of TEP in both genders might indicate the positive role of logical explanation for classroom activities that makes teachers teach with insight into teaching tasks. It is revealed that teachers, regardless of gender, reflect on enhancing teaching knowledge, principles, and experiences in the light of philosophical premises for classroom practice. It shows that teachers need to attend teacher development programmes in which they learn to put new perception into practice not only by thinking about what to teach and how to teach it, but also by thinking about why to teach it. Winch (2012) highlights the role of such programmes to meet the teachers' need for philosophical reflection on teaching and learning issues in classroom and to persuade teachers to make professional judgment about the reasons and results of classroom activities.

The data analysis to the second question showed a significant difference between the participant teachers in the experimental and control groups over the awareness of TEP. That is, both Master and Bachelor holders in experimental group demonstrated better 
perception than that of teachers in control group claiming that awareness of TEP develops teachers' PK. The difference revealed the degree-based knowledge is not the single benchmark for an effective teacher so that teachers must constantly seek the philosophical insight for the various aspects of classroom activities. Likewise, the classroom observation results showed better perception among teachers of experimental group indicating the consistency of questionnaire results to observation ones.

The reason of such difference between the perceptions of the two groups might be due to the lack of addressing English language teachers' insights into theories, practices and praxis in English language classrooms in Iran. The significance of TEP for teacher development particularly to enhance Iranian EFL teachers' professional knowledge has been highlighted and policy makers and training providers are requested to include it in the programmes (Ahmadi, 2007; Ananisarab \& Mobasher, 2009; Izadinia, 2015; Khanjani et al., 2016). As teaching engages in- and pre-service teachers in continuous enlightenment and development in personal and professional affairs, they should attend teacher education programmes and follow philosophy-based language teaching approach (Dabbagh \& Noshadi, 2016).

The third question addresses three groups of teachers with teaching experience for 1-10, 11-20, and plus 20 years. The data analysis showed homogeneity among three packs of teachers in each group. However, there was a significant difference between teachers of experimental and control groups. Teachers of experimental group indicated better perception of TEP than teachers in control group showing that awareness of TEP affects teacher's PK.

The possible account for this result is that development of PK can take place when the training programmes provide teachers with insight into decisions and judgements in their theories, practices, views and positions relevant to teaching. It is revealed that teachers should perceive not only what is to happen but also why it is to happen in the classroom through developing their ideas to connect their theoretical and practical knowledge to their teaching actions (Kheirzadeh \& Sistani, 2018). Programmes that offer thinking strategies, problem-solving abilities, insights into tasks, and judgements over the reasons and results of the teaching and learning issues can appropriately enhance 'knowledge that or propositional knowledge' and 'knowledge how or practical knowledge' of participant teachers (Winch, 2012). Regardless of teacher's gender, degree, experience, and age, a basic mission for teacher education programmes in L2 context is to develop teacher's sense of perspective and turn teacher to a "philosophy buff" (Crookes, 2009, p. 2).

The data analysis of the fourth research question relevant to teachers in three age ranges: $25-35,36-45$, and plus 45 in the experimental group showed no significant difference in mean values and neither did it happen to control group. Nevertheless, teachers participated in the experimental group displayed better perception towards the presented TEP in the programme; that is, awareness of TEP developed teacher' PK.

Lacking significant difference among the three age ranges in the same group might be due to the analogous exposure to the content that each group received. On the one hand, 
the experimental group underwent an innovative package of philosophical grounds to education and learnt fresh premises about teaching and learning so that almost all participants showed positive perception towards the presented philosophy in the programme. On the other hand, control group experienced materials that they may have passed as college credits before they started actual teaching profession; hence, they found book-reading period encompassing senescent and hackneyed subjects so that they showed negative perception. Shim (2008) explains the role of a teacher in Plato, Confucius, Buber, and Freire's eyes as a reviewer of old materials and realizer of new materials who discovers new points to teach them to learners.

Observation sessions also indicated the higher means and medians in the experimental group with sigma index $(0.00)$ revealing that there is a significant difference between two groups in implementing the premises of TEP presented in the teacher education programme for the classroom proceedings. That is, teachers in experimental group who were exposed to the certain attributes brought them to the classroom in practice, whereas teachers in the control group failed to do so.

\section{CONCLUSION}

The research findings of this study indicate that TEP affects EFL teachers' PK in a positive way. The results show that teachers of experimental group can implement absorbed insights and premises that are presented through the teacher education programmes in the real classroom activities. The philosophical perspective of classroom teachers influences their teaching styles, irrespective of their gender, academic level, teaching experience, and age. Teacher's enlightenment after treatment related to philosophy influences teachers' achievement both in perception and action associated with classroom activities (Erkilic, 2008 \& Saritas, 2016). The results of data extracted from the questionnaires showed teachers development in perception of the effect of TEP on their teaching knowledge, and the data analysis of observation sessions revealed the practical employment of the axioms of TEP in line with postmethod parameters in EFL context.

Furthermore, the results presented a considerably statistic index for the participants in experimental group. That is, the mean score of female teachers reached higher than the male ones, teachers holding bachelor degree showed stronger mean than those holding master degree, teachers having more experience in ELT indicated larger mean than teachers with less teaching experience, and teachers in second age range (11-20) displayed better mean than two other ranges. The findings of experimental group, in general, expressed that teachers who are extensively engaged in teaching language in EFL context take more advantage of TEP than teachers with less teaching involvement.

As TEP develops teachers' insight and judgement about what to teach, how to teach it, and why to teach it, teachers act as reflective professionals who need to involve in appropriate decisions over what-how-why premises through judgmental practices. Such practices improve the perspective of teachers on classrooms activities and provide changes in methodology, assessment, and teaching (Pacheco, 2005). 
Since this study employed a mixed-method approach as an initial effort in examining the effect of awareness of philosophy on EFL teachers' PK, it is suggested to employ distinct quantitative and qualitative approaches. Quantitative studies with more sample members might provide more reliable data and qualitative research might achieve thick and in-depth information on EFL teachers' perspective towards the role of philosophy. Besides, as the present study was mainly theory-based over EFL teachers' professional knowledge, research should be conducted to investigate the effect of philosophy on EFL teachers' professional skills to perceive the benefits of pedagogic options, tasks, projects, and techniques in more practice-based.

\section{IMPLICATIONS OF THE STUDY}

The pedagogical implications of the study can be viewed from four different perspectives. The findings may pave the way for education policy-makers in outlining materials over the philosophy of education to enable EFL teachers to discover, develop, and discipline their knowledge and abilities for self-development and productive work. Additionally, EFL teacher educators need to revisit development and strategies in teaching English language by holding reciprocal and dialogical collaboration and follow a postmethod framework in which they do not present merely prearranged materials in lecture-oriented sessions as a sole prolocutor. School administrators also observe the tangible results of the programmes in school classes so that they can offer objective feedback on the efficiency of the programmes. Teachers as the foremost figures benefit from philosophy-based teacher education programmes since they not only receive deep insight into their PK and PS in teaching English language, but also have access to other neighbouring sciences that have language related disciplines. As Day (2004) states, teachers, who attend dialogical-based programmes, express their commitment and enthusiasm in the profession and attempt to reflect on the programmes. Furthermore, Townsend and Bates (2007) focus on flexibility in the teaching approach as an outcome of interchange programme particularly in postmodern era for it enhances teacher quality.

\section{REFERENCES}

Ahmadi, P. (2007). An appraisal of foreign language teaching in Iran: The present state of the art. Roshd FLT Journal, 84 (22), 25-31.

Ananisarab, M \& Mobasheri, A. (2009). The impact of short-term pre-service teacher training courses on the teachers' attitude and practice. Roshd FLT Journal, 92 (24): 5465.

Apps, J. W. (1985). Improving practice in continuing education. San Francisco, CA: Jossey-Bass.

Renani, G. A. (2011). Perceptions of EFL teachers in Isfahan high schools towards professional knowledge and skills developments through short term in-service programmes. Master thesis. University Putra Malaysia, Malaysia.

Bakhtin, M. (1981). The dialogic imagination: Four essays by M. M. Bakhtin. Austin: University of Texas Press. 
Best, J. W., \& Khan, J, V. (2006). Research in education. ( $3^{\text {rd }}$ Ed.). New York: Pearson.

Brookfield, S. D. (1990). The skilful teacher: On technique, trust, and responsiveness in the classroom. San Francisco, CA: Jossey-Bass.

Buckmann, M. Floden, R. (1990). On doing philosophy in teacher education. Oxford Review of Education. 16 (3), 243-366.

Cattley, G. (2007). Emergence of professional identity for pre-service teacher. International Educational Journal, 8 (2), 337-347.

Conti, G. (2004). Identifying your teaching style. In M.W. Galbraith (Ed), Adult learning methods $\left(3^{\text {rd }}\right.$ ed.). Malabra, FL: Kreiger Publishing.

Crookes, G. (2009). Values, philosophies, and beliefs in TESOL: making a statement. Cambridge University Press: Cambridge.

Czerniawski, G. (2011). Emerging teachers-emerging identities: trust and accountability in the construction of newly qualified teachers in Norway, Germany, and England. European Journal of Teacher Education, 34 (4), 431-447.

Dabagh, A., \& Noshadi, M. (2016). Philosophy-based language teaching approach on the horizon: A revolutionary pathway to put applied ELT into practice. Journal of Language Teaching and Research, 7 (5), 1022-1028.

Day, C. (2004). A passion for teaching. UK: Routledge Falmer.

Day, M., \& Amstutz, D. D. (2003). Beyond philosophical identification: Examining core values in adult education. Adult Education Research Conference, San Francisco 216 State University, San Francisco, CA. Retrieved from http://michaelday.org/adulteducation/examing.

Derrida, J. (1982). Margins of philosophy. Trans Alan Bass Chicago: University of Chicago Press.

Dwyer, M., Maruyama, Y. \& Fontaine, H. (2011). Philosophy of education for the $21^{\text {st }}$ century: the projects of Heidegger and Wittgenstein. Revista de Filosofia. II Epoca, 6, 83-96.

Edge, J. (Ed.). (2001). Action Research. Alexandria, VA: TESOL.

Elias, J. L., \& Merriam, S. B. (2005). Philosophical foundations of adult education (3rd ed.). Malabar, FL: Krieger Publishing Company.

Elias, J. L., \& Merriam, S. B. (1980). Philosophical foundations of adult education (1st ed.). Malabar, FL: Krieger.

Erkilic, T. A. (2008). Importance of Educational philosophy in teacher training for educational sustainable development. Middle-East Journal of Scientific Research, 3 (1), $1-8$. 
Foucault, M. (1997). Madness and civilization: a history of insanity in the age of prison. London: Routledge.

Fries CH (2012). Teaching style preferences and educational philosophy of teacher education faculty at a state university. (Ph.D. dissertation) Oklahoma State University: United States.

Galbraith, M. W. (1999). Philosophy and instructional process. Adult learning methods. 11 (2), 11-22. In Strout, L. J. (2015). Philosophy within practice: relationship between philosophical orientations and teaching styles of faculty in early childhood teacher preparation programs. Unpublished dissertation. https://pqdtopen.proquest.com/doc/1759634898.html.

Giroux, H. (1999). Teachers as intellectuals. Connecticut: Greenwood Publishing Group.

Gutek, G. L. (2004). Philosophical and ideological voices in education. Boston: Allyn and Bacon.

Holzman, L. (2009). Vygotsky at work and play. East Sussex: Routledge.

Hug, R. (2015). Postmethod pedagogy: A survey of the English medium schools in Dhaka. Master thesis. BRAK University: Dhaka.

Izadinia, M. (2015). In search of a lost identity: Iranian women and their identity issues. Journal of International Women's Studies, 16(2), 128-257.

Johnson, K. E. (2006). The sociocultural turn and its challenges for second language teacher education. TESOL Quarterly, 40 (1), 235-257.

Khanjani, A., Vahedy, F., \& Jafarigohar, M. (2016). The EFL pre-service teacher training in Iran: Is it Adequate or not? Iranian Journal of English for Academic Purposes. 5 (1), 3-25.

Kheirzadeh, S. \& Ssitani, N. (2018). The Effect of reflective teaching on Iranian EFL students' achievement: The case of teaching experience and level of education. Australian Journal of Teacher Education, 43 (2), 143-156.

Kumar, A. (2015). Participatory adult learning, documentation and information networking unit 3: Philosophical background of adult and lifelong learning. New Delhi, India: Indira Gandhi National Open University (IGNOU). Retrieved from: http://www.unesco.org/education/aladin/paldin/pdf.

Kumaravadivelu, B. (2008). Cultural globalization and language education. New Haven, CT: Yale University Press.

Kumaravadivelu, B. (2001). Towards a postmethod pedagogy. TESOL Quarterly, 35, 537-560.

Kumaravadivelu, B. (2012). Language teacher education for a global society. New York: Routledge. 
Kumaravadivelu, B. (2006). Understanding language teaching: from method to post method. New Jersey: Lawrence Erlbaum Associates.

Larsen-Freeman, D. \& Anderson, M. (2011). Techniques \& principles in language teaching. Oxford: Oxford University Press.

Longford, Peter. E. (2005). Vygotsky's developmental and educational psychology. East Sussex: Psychology Press.

Merriam, S.B., \& Brockett, R. (2007). The Profession and Practice of Adult Education: An Introduction. San Francisco: Jossey-Bass.

Norton, B. (2000). Identity and Language Learning. London: Longman.

O'Hanlon, C. (1993). The importance of an articulated personal theory of professional development. In J. Elliott (ed.). Reconstructing teacher education: Teacher development (pp. 243-55). London: The Falmer Press.

Ornstein, A. C., \& Levine, D. U. (2003). Foundations of education (8th ed.). Boston: Houghton-Mifflin.

Ozmon, H. A., \& Craver, S. M. (2003). Philosophical foundations of education (7th ed.). New Jersey: Merrill Prentice Hall.

Pacheco, A. Q. (2005). Reflective teaching and its impact on foreign language teaching. Revisit Electronica “Act alidades Investigative en Education”, 5, 1-19.

Saritas, E. (2016). Relationship between philosophical preferences of classroom teachers and their teaching styles. Education research and Reviews, 11 (16), 1533-1542.

Shim, S. H. (2008). A philosophical investigation of the role of teachers: A synthesis of Plato, Confucius, Buber, and Freire. Teaching and Teacher Education, 24, 515-535.

Smitherman, G. (2000). Talking with talk: language, culture and education in African America. London: Routledge.

Tan, C (2006). Philosophical perspectives on education. In Tan, C., Wong, B., Chua, J.S.M. \& Kang, T. (Eds.), Critical perspectives on education: An introduction (pp. 2140). Singapore: Prentice Hall.

Tenet, J. (2010). Teacher education as identity construction: Insights from action research. Journal of Education for Teaching, 36 (2), 153-168.

Townsend, T., \& Bates, R. (2007). Handbook of teacher education: globalization, standards and professionalism in times of change. Springer: The Netherlands.

Winch, C. (2012). For philosophy of education in teacher education. Oxford Review of Education. 38 (3), 305-322.

Zinn, L. M. (2007). Philosophy of adult education inventory. Quincy, IL: Lifelong Learning Options. 